\title{
Capture Myopathy: An Important Non-infectious Disease of Wild Animals
}

\author{
M. Dinesh ${ }^{1}$, Jigarji C. Thakor ${ }^{1}$, Hiteshwar Singh Yadav ${ }^{1}$, \\ R. Manikandan', S. Anbazhagan', E. Kalaiselvan ${ }^{3}$, R. Pradeep 4 , \\ Rajpal Shesherao Khillare ${ }^{5}$ and Monalisa Sahoo ${ }^{1 *}$
}

\author{
${ }^{1}$ Division of Pathology, ICAR-Indian Veterinary Research Institute, U.P, India \\ ${ }^{2}$ Division of Veterinary Microbiology, ICAR-Indian Veterinary Research Institute, U.P, India \\ ${ }^{3}$ Division of Veterinary Surgery, ICAR-Indian Veterinary Research Institute, U.P, India \\ ${ }^{4}$ Department Wildlife Science, Madras Veterinary College, TANUVAS, T.N, India \\ ${ }^{5}$ Department of Veterinary Public Health, Mumbai Veterinary College, MAFSU, M.H, India
}

*Corresponding author

\section{A B S T R A C T}

\section{Keywords}

Capture myopathy,

Muscle, Lameness,

Wild animals

Article Info

Accepted:

10 March 2020

Available Online:

10 April 2020
Capture myopathy appears primarily when wild animals are captured. The important signs of $\mathrm{CM}$ are an enormous increase in body temperature, muscle spasms, stiffness lameness, recumbent, the appearance of dark red colored urine and finally, ends with Death. Large muscles of the hind limb affected commonly. It is very difficult to treat once clinical signs become apparent. The condition carries a grave prognosis. Apart from wildlife, domestic animals and humans are also affected by these conditions with similar pathophysiology. This review aims to highlight the current state of knowledge and a better understanding of clinical and pathophysiological presentation, treatments, and preventive measures of capture myopathy in wild animals.

\section{Introduction}

Every wildlife rancher, wildlife translocator, veterinarian and wildlife auctioneer fear these words: capture myopathy. The so-called condition is the Achilles heel of the wildlife industry. Capture myopathy $(\mathrm{CM})$ is a noninfectious, metabolic disease of wild and domestic animals that can lead to significant morbidity and mortality. The condition is most commonly associated with pursuit, capture, restraint, transport, secondary to other diseases and natural hazards encountered in the environment. It is characterized by metabolic acidosis, muscle necrosis, and myoglobinuria. 
Clinical signs include muscle stiffness, severe muscle pain, ataxia, paresis, torticollis, prostration, and paralysis. Animals typically become obtund, anorexic, and unresponsive. Death can occur from within minutes or hours of capture to days or weeks after the inciting event. The first recorded pathological description of capture myopathy was from 1964 in Hunter's hartebeest (Beatragus hunteri), currently one of the most critically endangered antelope species (Jarrett et al., 1964) (Fig. 1 and 2).

CM has been termed muscular dystrophy, white muscle disease, overstraining disease, capture disease, cramp, leg paralysis, spastic paresis, stress myopathy, transport myopathy, incipient myopathy, degenerative polymyopathy, muscle necrosis, and idiopathic muscle necrosis throughout the literature.

The condition is now most commonly referred to as $\mathrm{CM}$, exertional myopathy, or exertional rhabdomyolysis (Spraker, 1993). Capture myopathy (CM) in wildlife may be a model for stress cardiomyopathy (e.g. Takotsubo Syndrome, Broken-Heart Syndrome) in humans. Peracute CM (a subtype of CM in which symptoms emerge soon after exposure to the stressor) in particular, shares many features with Takotsubo Syndrome/Broken-Heart Syndrome in humans (Blumstein et al., 2015).

\section{Etiology}

Exertional rhabdomyolysis, or CM, in animals is distinguishable from other types of rhabdomyolysis by its pathophysiology, as it affects both skeletal and cardiac muscles in response to extreme stress and muscular exertion. $\mathrm{CM}$ is an inherent mechanism that facilitates a symbiotic relationship between predator and prey. The stresses of fear and anxiety are the triggering mechanisms for $\mathrm{CM}$ that may be modified by genetic or acquired predispositions to the disease (Meyer, 2009). These factors, in turn, may be exacerbated by iatrogenically induced circumstances, such as overexertion, disturbance, excessive handling, transportation, and shock. It is a complex and multifactorial disease (Landau et al., 2012).

\section{Predisposing factors}

There are many predisposing or contributing factors for CM which include Species, Environment, Capture related, Other diseases, Nutrition Drugs, and Signalment.

\section{Species}

Prey species are considered the most susceptible to $\mathrm{CM}$ in the mammalian taxa, particularly ungulates. Highly susceptible species include zebra, deer, giraffe, nyala, tsessebe, duiker, roan antelope, red hartebeest, eland, springbok, kudu, giraffe, white-tailed deer, pronghorn, fallow, and hog deer. The long-legged wading birds are particularly predisposed to $\mathrm{CM}$ within the avian taxa. The combination of struggle during capture and restraint in bags or cages where the birds cannot stand increases their susceptibility to $\mathrm{CM}$. Reports of CM in carnivores are rare but the disease can occur under certain conditions (Cattet et al., 2008).

\section{Environment}

Environmental factors that can increase the incidence of CM include extremes in ambient temperature, rain, and high humidity. The need for animals to negotiate steep terrain, difficult footing, or water hazards can also hasten the onset of CM.

\section{Capture related}

Capture-related factors that contribute to $\mathrm{CM}$ comprise the largest category. Capture 
techniques that involve high chase speeds, prolonged exertion without rest, excessive handling, prolonged restraint, the restraint that promotes struggling from unnatural positioning, crating, transport, subjection to fear stimuli over periods, and renewed stresses, such as repeated moving and transport predispose animals to CM (Ebedes et al., 2002). Injuries induced by capture techniques, or by other animals, can also increase the incidence of CM.

\section{Other diseases}

Underlying diseases and infections can make an animal more susceptible to CM. Severe worm and tick infections cause anemia and weaken the animal. Heartworm infection may compromise cardiopulmonary circulation (Lin et al., 2006).

\section{Nutrition}

Animals with a pre-existing vitamin $\mathrm{E}$ or selenium deficiency may be predisposed to developing CM. Individuals on a high nutritional plane and carrying excess body fat, such as premigratory birds, may also be at higher risk (Hebert et al., 1971).

\section{Drugs}

Potent opioids, such as fentanyl, etorphine, carfentanil, and thiafentanil, are often used in combination with alpha-2 agonists, butyrophenones, benzodiazepines, and cyclohexamines for wildlife capture (Paterson et al., 2009). Wildlife species immobilized with opioid-based combinations frequently demonstrate side effects, such as excitement, spontaneous movement, muscle rigidity, hypoventilation, catecholamine release, and hyperthermia (Radcliffe et al., 2000). These effects, combined with hypoxemia and elevated fluid loss, may significantly increase the risk of CM. It is important to recognize that nonopioid drug combinations can also cause similar side effects and predispose anesthetized animals to CM (Caulkett et al., 2000).

\section{Signalment}

Extremely old and extremely young animals may be the most susceptible to CM in certain circumstances. Males and pregnant animals are considered more susceptible to CM. Estrogens have a protective effect, therefore, reducing the risk for female animals (Lin et al., 2006; Rogers et al., 2004).

\section{Pathophysiology}

Pathogenesis of $\mathrm{CM}$ as involving three primary components: perception of fear, sympathetic nervous and adrenal systems, and muscular activity (Spraker, 1993; Vanholder $e t$ al., 2000; Paterson, 2007)

\section{Clinical and pathological syndrome}

Rhabdomyolysis literally means "dissolution of striped (skeletal) muscle". Exertion induced rhabdomyolysis leads to the breakdown of skeletal muscle fibers with leakage of intracellular contents, including creatinine kinase $(\mathrm{CK})$ and myoglobin into the blood. CK elevation more than 10 times the upper reference limit, myoglobinuria, hyperkalemia, and coagulopathy.

CK concentration greater than $10,000 \mathrm{U} / \mathrm{L}$ in horses is indicative of myopathy (reference range 60-330 U/L) (Volfiger et al., 1994). Signifiant muscle injury in captured grizzly and black bears was diagnosed at CK levels greater than $387 \mathrm{U} / \mathrm{L}$ (reference range 0-387 $\mathrm{U} / \mathrm{L}$ ) and $421 \mathrm{U} / \mathrm{L}$ (reference range 0-421 U/L), respectively (Cattet et al., 2008). Spraker (1993) described four primary CM syndromes: capture shock, ataxic myoglobinuric, ruptured muscle and delayed 
peracute. When classifying specific clinical signs and gross and histologic findings into different syndromes of CM, it is important to recognize that the pathogenesis of $\mathrm{CM}$ is a continuum; some animals may show clinical signs and pathology that overlap one or more syndromes.

Affected muscles: Large muscles of limb (gluteus, biceps femoris, semimembranosus, semitendinosus and gastrocnemius) also pectoral, intercostals and cardiac muscle Lesions tend to be bilateral and symmetrical.

\section{Hyperacute or capture shock syndrome}

Acute death syndrome can occur during immobilization or within a short time after capture. Death usually occurs within 1-6 hours postcapture. Clinical signs include depression, hyperpnea/ tachypnea, tachycardia, elevated body temperature, weak thready pulses, and death. Serum biochemical findings include elevations in serum aspartate aminotransferase (AST), creatinine phosphokinase (CK), and lactate dehydrogenase (LDH) enzyme (Paterson, 2014).

The most common PM lesions include severe small intestinal and hepatic congestion along with pulmonary congestion and edema. Frank blood and blood-tinged contents may be found within the lumen of the small intestine. Histologic findings may include small areas of necrosis in skeletal muscle, brain, liver, heart, adrenal glands, lymph nodes, spleen, pancreas, and renal tubules (Harthoorn et al., 1974). Small thrombi may occasionally be found in the capillaries in various organs (Spraker, 1993).

\section{Acute or ataxic myoglobinuric syndrome}

This is the most commonly observed among the four syndromes. It may become evident several hours to several days postcapture.

Clinical signs may include mild to severe ataxia, torticollis, and myoglobinuria. Serum enzymes (AST, CK, and LDH) and blood urea nitrogen (BUN) levels are elevated. Animals demonstrating mild signs are the most likely to survive (Harthoorn et al., 1974).

Animals with moderate to severe symptoms have higher mortality. Gross lesions can be seen in the kidneys and skeletal muscle. The kidneys are swollen and dark. The urinary bladder is empty or contains a small amount of brownish urine.

The cervical and lumbar muscles, as well as the flexor and extensor muscles of the limbs (appendicular skeleton), contain multifocal, pale, soft, dry areas, accentuated by small white foci in a linear pattern (Roe and Spraker, 2012). The lesions are bilateral. They are subtle in animals that die within 1-2 days after capture, but they are more pronounced in chronic cases.

Animals with prolonged survival may have small ruptures within the necrotic muscles. Well-demarcated, gross changes to the hindlimb musculatures. Histologic lesions are primarily localized to the renal cortex and skeletal muscle.

Renal lesions are characterized by dilatation of tubules, moderate to severe tubular necrosis, and protein (myoglobin) casts (Blumstein et al., 2015). Muscular lesions are characterized by acute rhabdomyolysis. Myocytes are markedly swollen, with loss of striations and fragmentation and cleavage of myofibrils. Sarcolemmal nuclei are pyknotic in multiple areas. Sarcolemmal proliferation usually begins within 3 days of capture (Spraker 1993). 


\section{Subacute or ruptured muscle syndrome}

Clinical signs of this syndrome do not usually manifest until 24-48 hours postcapture and animals initially appear normal. Physical exam findings include a marked drop in the hindquarters and hyperflexion of the hock due to unilateral or bilateral rupture of the gastrocnemius muscle. Extreme elevations in AST, CK, and LDH are present.

BUN may be within normal limits or slightly elevated. Although most animals with ruptured muscle syndrome die within a few days, some may survive for several weeks (Breed et al., 2019). Gross examination reveals massive subcutaneous hemorrhage of the rear limbs, and multifocal small to large, pale, soft lesions in the forelimb, hindlimb, diaphragm, cervical, and lumbar muscles (Lewis et al., 1977). Muscular lesions are similar to those described for the ataxic myoglobinuric syndrome but they are more severe and widespread.

Lesions are bilateral but not symmetrical. Multiple, small to large ruptures may be found in necrotic muscle bodies (Harthoorn et al., 1974). The gastrocnemius, subscapularis, middle and deep gluteal, semitendinosus, and semimembranosus muscles are often ruptured. Histologic lesions are primarily located within the skeletal muscles and they are characterized by severe, diffuse necrosis (Spraker 1993). More extensive sarcolemmal proliferation, fibrosis, and muscular regeneration are evident in ruptured muscle syndrome compared to the ataxic myoglobinuric syndrome.

\section{Chronic debility or delayed peracute syndrome}

This syndrome occurs rarely. Harthoorn (1976) also referred to this phase as the 'indefinite phase'. Typically, these animals have been captured at least once in the past When they are exposed to a second, usually mild stressful event (often another capture), death occurs within a few minutes (Montane et al., 2002). This syndrome is rare but can be seen in animals that have been in captivity for at least 24 hours.

The animals appear normal if they are left undisturbed. When disturbed, captured, or acutely stressed, they will try to escape or run but stop abruptly and stand or lie still for a few moments. During this period, their eyes begin to dilate and death ensues within several minutes. These animals die in ventricular fibrillation and have elevated AST, CK, and LDH (Chalmers et al., 1977).

There are usually no lesions or a few small pale foci within the skeletal muscle at necropsy. When present, histologic lesions are characterized by mild to moderate rhabdomyolysis throughout the skeletal muscle, especially in the hindlimbs (Spraker 1993; Montane et al., 2002).

\section{Diagnosis}

Conclusive diagnosis of $\mathrm{CM}$ depends on history, clinical signs, clinical pathology, and gross and microscopic pathology.

\section{Differential diagnosis}

Differential diagnosis for $\mathrm{CM}$ in wildlife may include white-muscle disease, plant toxicities such as Cassia occidentalis, Cassia obtusifolia, and Karwinskia Humboldtian, malignant hyperthermia, early tetanus, hypocalcemia, and myositis.

\section{Treatment}

Treatment of CM generally has a low success rate, although animals have been rehabilitated with intensive efforts. Costs and logistics 
associated with treating wild animals, particularly in field situations, pose significant challenges. Potential treatment options are discussed below.

\section{Analgesia}

Animals suffering from $\mathrm{CM}$ can experience severe muscle pain. Analgesia should be considered from an ethical and prognostic point of view. The distress and anxiety resulting from pain will make this disease more difficult to treat.

Analgesics used will vary depending on the affected species. Judicious use of nonsteroidal anti-inflammatories is an option provided there is no concurrent steroid administration or indication of renal dysfunction (Paterson, 2014; Muir et al., 2000). Opioid administration with or without a sedative should also be considered. Corticosteroids may alleviate pain and help preserve lysosomal membrane and capillary integrity.

\section{Dantrolene}

Dantrolene sodium is a lipid-soluble hydantoin analog used to treat and prevent malignant hyperthermia in humans and exertional rhabdomyolysis in horses. Dantrolene suppresses the release of calcium from the sarcoplasmic reticulum (Choi et al., 2017). Side effects associated with dantrolene include neurologic illness, muscular weakness, and hepatoxicity. The drug would be impractical for field use due to its light sensitivity, insolubility, and expense (Wells et al., 2009).

\section{Muscle relaxants}

Benzodiazepines, including diazepam, midazolam, and zolazepam, are centrally acting muscle relaxants that reduce muscle spasms and spasticity (Wolfe and Miller
2005). Methocarbamol is another centrally acting muscle relaxant that has been used to successfully treat CM (Ward et al., 2011). Limited pharmacokinetic data is available for this medication in veterinary species.

\section{Dietary supplements}

Vitamin E and selenium are biological antioxidants administered as a prophylaxis or treatment for CM (Abbott et al., 2005). Balanced formulation of $\mathrm{B}$ vitamins with vitamin C in parenteral form, Coenzyme Q10, and L-carnitine also used (El-Ashker, 2012).

\section{Hyperbaric oxygen}

Hyperbaric oxygen $\left(\mathrm{HBO}_{2}\right)$ has been used as adjunctive therapy. It induces high oxygen partial pressure in all tissues, inhibits toxin formation, and promotes wound healing (Abdullah et al., 2006; Parikh et al., 2009; Bagley et al., 2007). The popularity of this therapy in veterinary medicine is increasing and may become more accessible in the future, particularly for highly valued captive animals.

\section{Sodium bicarbonate}

Sodium bicarbonate is used to treat acidemia and alkalinize the urine. Approximately 4 $\mathrm{mEq} / \mathrm{kg}$ of sodium bicarbonate administered intravenously is successful in resolving metabolic acidosis and reducing mortality in large animals (Wells et al., 2009).

Alkalinizing the urine can reduce the risk of tubular obstruction by myoglobin casts; however, myoglobin is also intrinsically nephrotoxic (Forsythe and Schmidt, 2000). Blood gas analysis should ideally be used to titrate sodium bicarbonate therapy. Excessive administration may produce metabolic alkalosis or paradoxical cerebrospinal acidosis (Smith et al., 2005). 


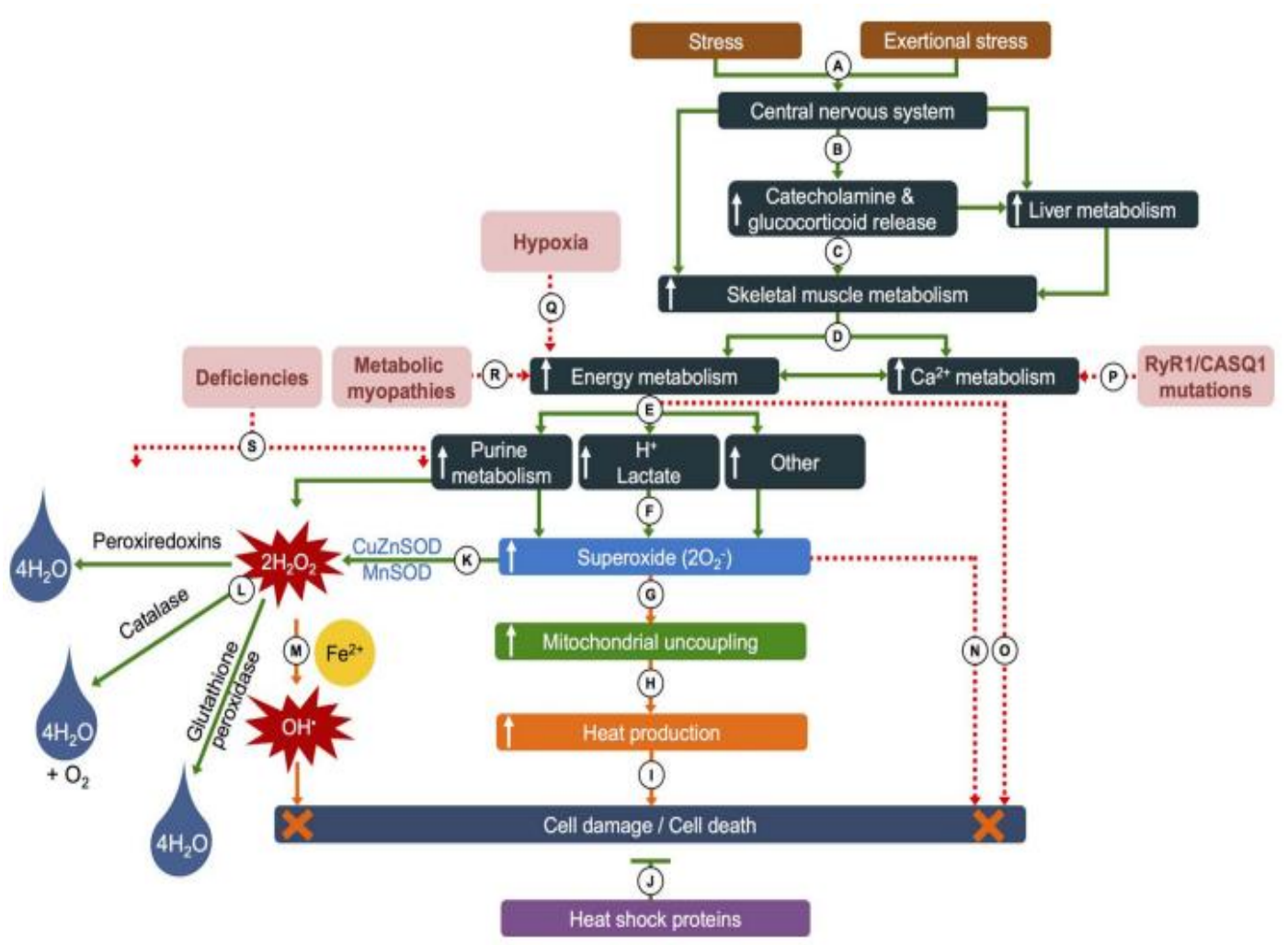

Fig.1 Brief, possible pathomechanisms of Capture myopathy in wild animals (Breed et al., 2019)

(A) Stimuli in the form of fear and/or exertional stress (typical fight or flight response), with the central nervous system reacting to the stimuli.

(B) Increase in sympathetic nervous activation and increased adrenalin, noradrenalin, dopamine, and glucocorticoid secretion and release, as well as increased liver metabolism and skeletal muscle activity.

(C) Increased catecholamine secretion upregulates skeletal muscle metabolism.

(D) Increased ATP production from glycogen breakdown and phosphagen pathways in response to the demand from skeletal muscle contraction-myosin ATPase activity, active $\mathrm{Ca} 2{ }^{+}$resorption into sarcoplasmic reticulum and the $\mathrm{Na}^{+} \mathrm{K}^{+}$ATPase pumps.

(E) The increased demand for ATP replenishment results in elevated purine metabolism increased lactate and $\mathrm{H}^{+}$ production.

(F) Increased generation of reactive oxygen species (ROS), such as superoxide $\left(\mathrm{O}_{2^{-}}\right)$.

(G) The increase in $\mathrm{O}_{2}$ results in greater uncoupling of oxidative phosphorylation

(H) Increases heat production from the skeletal muscle.

(I) An elevation in muscle temperature increases the risk of muscle fiber damage and necrosis

(J) Damage counteracted by the protective effect of heat shock proteins.

(K) $\mathrm{O}_{2}$-is converted to hydrogen peroxide $\left(\mathrm{H}_{2} \mathrm{O}_{2}\right)$ by superoxide dismutase (SOD), which requires zinc, copper, and manganese to function optimally.

(L) Three pathways neutralize the $\mathrm{H}_{2} \mathrm{O}_{2}$ to water (peroxiredoxins and glutathione peroxidase that requires selenium to function optimally) and oxygen (catalase).

(M) If not neutralized, $\mathrm{H}_{2} \mathrm{O}_{2}$ may be converted to hydroxy radical molecules $(\mathrm{OH} \cdot)$ through the Fenton reaction (involving iron) that can cause severe cellular damage.

(N) Excess ROS especially in the form of $\mathrm{O}_{2}$-may cause cellular damage.

(O) A lack of ATP replenishment as a result of excessive metabolism [e.g. glycogen depletion or (Q) hypoxia] prevents the myosin-actin cross-bridges to detach (a form of rigor) and leads to damaged muscle fibers through the mechanical stretch. Mutations in receptors involved in $(\mathrm{P}) \mathrm{Ca}_{2}{ }^{+}$regulation or $(\mathrm{R})$ ATP production can result in muscle damage through the same mechanism proposed in $(\mathrm{O})$.

(S) Mineral deficiencies (co-factors) within the oxidative stress pathway enzymes can

lead to diminished antioxidant capacities, leading to excess ROS that may injure cell membranes. 

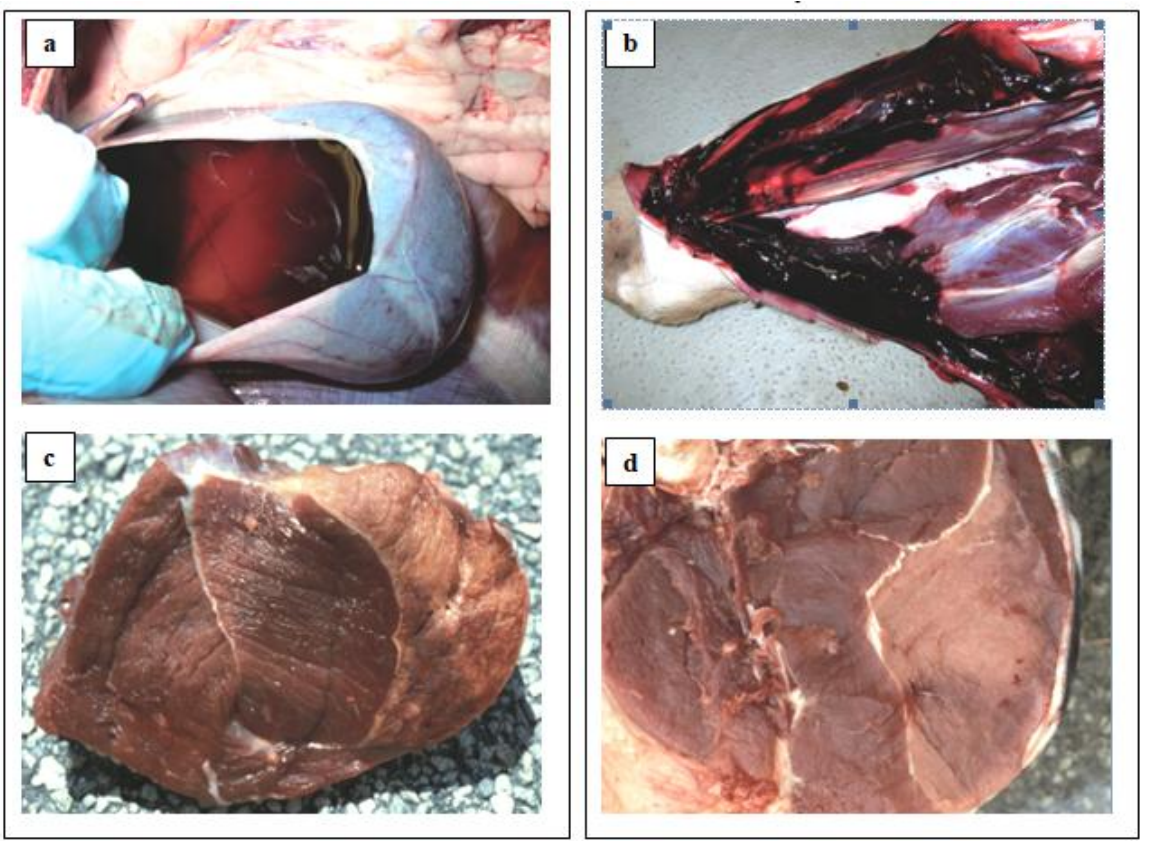

Fig.2 Gross pathology of Capture myopathy

(a) Urinary bladder of white-tailed deer showing marked myoglobinuria. (b) Left hindlimb of white-tailed deer showing marked subcutaneous hemorrhage proximal to the tarsus and exhibiting ruptured muscle syndrome. The left lateral musculature is exposed with the tarsus on the left.(Photo (a\&b): Dr.Douglas Whiteside). (c) Hindlimb adductor muscle of nilgai showing sharp demarcation between normal muscle on the left hand side and the affected muscle on the far right that has a pale,dry appearance. (d) Gluteal musculature on the far right of zebra showing pale in color, appears to have a dry surface and it is isolated from normal muscle by a septum of deep fascia.(Photo (c\&d): Dr. Scott Citino). (Reference: Paterson, 2007)

\section{Prevention}

Possible modes of preventing CM will depend largely on the species being captured, the goal of capture, the resources available, and the environment in which the capture is taking place.

Operators must recognize environmental limitations, such as extremes in temperature or terrain.

Handling should be minimal and performed by experienced personnel. Transportation must be as brief as possible and appropriate for the species and individual.

Providing food, water, and nutritional supplements to captured animals, particularly during prolonged transport or upon reaching the new destination.

Drugs chosen for immobilization should be tailored for rapid induction, rapid recovery, efficient delivery, and physiologic stability.

Duration of anesthesia should be as short as possible and oxygen supplementation is generally recommended

Hyperthermia is believed to play a role in the development of capture myopathy. Therefore, it has become a common practice to attempt to actively cool animals that develop capture-induced hyperthermia.

Survival rates were improved by reducing chase speeds, allowing periodic rests during the drive.

Transporting to the destination immediately after capture with no holding or quarantine, using plastic sheeting or Hessian funnels and corrals. 
Reducing fear and stress by eliminating shouting and other noise, and ensuring minimal contact between the animals and the capture personnel.

\section{Fluid therapy}

Intravascular volume expansion with balanced electrolyte solutions is effective in treating metabolic acidosis, hyperkalemia, dehydration, and myoglobinuria. Intravenous fluid therapy may also help to offset hypotension that occurs in some cases of CM (Businga et al., 2007; Valberg, 2009).

\section{Nutritional supplementation}

Animals suffering from CM will usually not meet their nutritional requirements voluntarily. Decreased body condition, nutritional deficiencies, and weight loss may significantly impact prognosis. Nutritional supplementation is a vital component in successful treatment (Rogers et al., 2004).Capture myopathy remains a frustrating and poorly understood condition despite being frequently reported in the veterinary literature.

Its unpredictable and multifactorial nature poses a distinct challenge to those who study the disease. The key to preventing CM lies in understanding the behavior and physiology of individual species. Developing a consistently effective treatment for $\mathrm{CM}$ will require a better understanding of how to stop the physiologic cascade once it has been triggered. The need for the increased success rates in the capture myopathy is further believed to have an inference in the conservation of wild animals and the verge of extinct endangered species too. Further research strategies are proposed to help better understanding the pathophysiology of capture myopathy, potential treatment, and preventive measures.

\section{References}

Abbott, C.W., Dabbert, C.B., Lucia, D.R. and Mitchell, R.B., 2005. Does muscular damage during capture and handling handicap radiomarked northern bobwhites? The Journal of wildlife management, 69(2), pp.664-670.

Abdullah, M.S., Noori, S., Butler, G. and Baban, N.K., 2006. Hyperbaric oxygen as adjunctive therapy for bilateral compartment syndrome, rhabdomyolysis and acute renal failure after heroin intake. Archives of medical research, 37(4), pp.559-562.

Bagley, W.H., Yang, H. and Shah, K.H., 2007. Rhabdomyolysis. Internal and emergency medicine, 2(3), pp.210-218.

Blumstein, D.T., Buckner, J., Shah, S., Patel, S., Alfaro, M.E. and Natterson-Horowitz, B., 2015. The evolution of capture myopathy in hooved mammals: a model for human stress cardiomyopathy?. Evolution, medicine, and public health,2015(1), pp.195-203.

Breed, D., Meyer, L.C., Steyl, J.C., Goddard, A., Burroughs, R., and Kohn, T.A., 2019. Conserving wildlife in a changing world: Understanding capture myopathy-a malignant outcome of stress during capture and translocation. Conservation Physiology, 7(1), p.coz027.

Businga, N.K., Langenberg, J. and Carlson, L., 2007. Successful treatment of capture myopathy in three wild greater sandhill cranes (Grus canadensis tabida). Journal of Avian Medicine and Surgery, 21(4), pp.294-298.

Cattet, M., Stenhouse, G. and Bollinger, T., 2008. Exertional myopathy in a grizzly bear (Ursus arctos) captured by leghold snare. Journal of Wildlife Diseases, 44(4), pp.973-978.

Caulkett, N.A., Cattet, M.R., Cantwell, S., Cool, N. and Olsen, W., 2000. Anesthesia of wood bison with medetomidinezolazepam/tiletamine and xylazine- 
zolazepam/tiletamine combinations. The Canadian Veterinary Journal,41(1), p.49.

Chalmers, G.A. and Barrett, M.W., 1977. Capture myopathy in pronghorns in Alberta, Canada. Journal of the American Veterinary Medical Association, 171(9), pp.918-923.

Choi, R.H., Koenig, X. and Launikonis, B.S., 2017. Dantrolene requires $\mathrm{Mg}$ + to arrest malignant hyperthermia. Proceedings of the National Academy of Sciences, 114(18), pp.4811-4815.

Ebedes, H., Van Rooyen, J. and Du Toit, J.G., 2002. Capturing wild animals. Game ranch management, pp.382-430.

El-Ashker, M.R., 2012. Diagnostic efficiency of selected biochemical variables to predict the clinical outcome of exertional rhabdomyolysis in Egyptian draft horses. Comparative Clinical Pathology, 21(5), pp.1103-1108.

Forsythe, S.M. and Schmidt, G.A., 2000. Sodium bicarbonate controversy in lactic acidosis. Chest, 118(3), p.882.

Harthoorn, A.M. and Van Der Walt, K., 1974. Physiological aspects of forced exercise in wild ungulates with special reference to (so called) overstraining disease. I. Acid base balance and Oxygen Partial Pressure levels in blesbok (Oamaliscus dorcas phillipsi). South African Journal of Wildlife Research-24-month delayed open access, 4(1), pp.25-28.

Harthoorn, L.M., 1976. Parentrovite as a supportive therapy for locomotory stress in tsessebe. Journal of the South African Veterinary Association, 47(3), pp.219222.

Hebert, D.M. and Cowan, I.M., 1971. White muscle disease in the mountain goat. The Journal of Wildlife Management, pp.752756.

Jarrett, W.H.F., Jennings, F.W., Murray, M. and Harthoorn, A.M., 1964. Muscular dystrophy in wild Hunter's antelope. African Journal of Ecology, 2(1), pp.158-159.

Landau, M.E., Kenney, K., Deuster, P. and
Campbell, W., 2012. Exertional rhabdomyolysis: a clinical review with a focus on genetic influences. Journal of clinical neuromuscular disease, 13(3), pp.122-136.

Lewis, R.J., Chalmers, G.A., Barrett, M.W. and Bhatnagar, R., 1977. Capture myopathy in Elk in Alberta, Canada: a report of three cases. Journal of the American Veterinary Medical Association, 171(9), pp.927-932.

Lin, H., Chie, W. and Lien, H., 2006. Epidemiological analysis of factors influencing an episode of exertional rhabdomyolysis in high school students. The American journal of sports medicine, 34(3), pp.481-486.

Meyer, L.C.R., 2009. Reduction of captureinduced hyperthermia and respiratory depression in ungulates (Doctoral dissertation, Thesis, University of the Witswatersrand, Johannesburg).

Montane, J., Marco, I., Manteca, X., Lopez, J. and Lavin, S., 2002. Delayed acute capture myopathy in three roe deer. Journal of Veterinary Medicine Series A, 49(2), pp.93-98.

Muir, W.W., 2000. Drugs used for preanesthetic medication. Handbook of veterinary anesthesia, pp.19-40.

Parikh, S., Saneto, R., Falk, M.J., Anselm, I., Cohen, B.H. and Haas, R., 2009. A modern approach to the treatment of mitochondrial disease. Current treatment options in neurology, 11(6), p.414.

Paterson J (2014) Capture myopathy. In G West, D Heard, N Caulkett, ds, Zoo Animal and Wildlife Immobilization and Anesthesia, Ed2nd.Blackwell Publishing, pp. 115-122

Paterson, J., 2007. Capture myopathy (pp. 115121). Blackwell Publishing, Oxford, UK.

Paterson, J.M., Caulkett, N.A. and Woodbury, M.R., 2009. Physiologic effects of nasal oxygen or medical air administered prior to and during carfentanil-xylazine anesthesia in North American elk (Cervus canadensis manitobensis). Journal of Zoo and Wildlife Medicine, 40(1), pp.39-50. 
Radcliffe, R.W., Ferrell, S.T. and Childs, S.E., 2000. Butorphanol and azaperone as a safe alternative for repeated chemical restraint in captive white rhinoceros (Ceratotherium simum). Journal of Zoo and Wildlife Medicine, 31(2), pp.196-200.

Roe, W. and Spraker, T.R., 2012. Capturerelated myopathy in marine mammals and exertional rhabdomyolysis in horses: A possible link? The Veterinary Journal, 1(193), pp.10-11.

Rogers, D.I., Battley, P.F., Sparrow, J., Koolhaas, A. and Hassell, C.J., 2004. Treatment of Capture Myopathy in Shorebirds: A Successful Trial in Northwestern Australia/(Tratamiento de Miopatía en playeros: casos exitosos en la parte noroeste de Australia). Journal of Field Ornithology, pp.157-164.

Smith, K.M., Murray, S. and Sanchez, C., 2005. Successful treatment of suspected exertional myopathy in a rhea (Rhea americana). Journal of Zoo and Wildlife Medicine, 36(2), pp.316-320.

Spraker, T.R., 1993. Stress and capture myopathy in artiodactylids. In 'Zoo and Wild Animal Medicine: Current Therapy'.(Ed. ME Fowler.) pp. 481-487.

Valberg SJ (2009) Exertional rhabdomyolysis: diagnosis and treatment. In Proceedings of the 11th International Congress of the World Equine Veterinary Association, Guaruja, Brazil.

Vanholder R, Sever MS, Erek E, et al., 2000. Rhabdomyolysis. Journal of the
American Society of Nephrology 11:1553-1561

Volfinger, L., Lassourd, V., Michaux, J.M., Braun, J.P. and Toutain, P.L., 1994. Kinetic evaluation of muscle damage during exercise by calculation of amount of creatine kinase released. American Journal of Physiology-Regulatory, Integrative and Comparative Physiology, 266(2), pp.R434-R441.

Ward, J.M., Gartrell, B.D., Conklin, J.R. and Battley, P.F., 2011. Midazolam as an adjunctive therapy for capture myopathy in bar-tailed godwits (Limosa lapponica baueri) with prognostic indicators. Journal of Wildlife Diseases, 47(4), pp.925-935.

Wells, R.J., Sedacca, C.D., Aman, A.M., Hackett, T.B., Twedt, D.C. and Shelton, G.D., 2009. Successful management of a dog that had severe rhabdomyolysis with myocardial and respiratory failure. Journal of the American Veterinary Medical Association, 234(8), pp.1049-1054.

Williams ES, Thorne ET. 1996. Exertional myopathy. In: Noninfectious Diseases of Wildlife, 2nd ed. (A Fairbrother, LL Locke, GL Hoff, eds.), pp. 181-193. Ames: Iowa State University Press.

Wolfe, L.L. and Miller, M.W., 2005. Suspected secondary thiafentanil intoxication in a captive mountain lion (Puma concolor). Journal of wildlife diseases, 41(4), pp.829-833.

\section{How to cite this article:}

Dinesh, M, Jigarji C. Thakor, Hiteshwar Singh Yadav, R. Manikandan, S. Anbazhagan, E. Kalaiselvan, R. Pradeep, Rajpal Shesherao Khillare and Monalisa Sahoo. 2020. Capture Myopathy: An Important Non-infectious Disease of Wild Animals. Int.J.Curr.Microbiol.App.Sci. 9(04): 952-962. doi: https://doi.org/10.20546/ijcmas.2020.904.114 